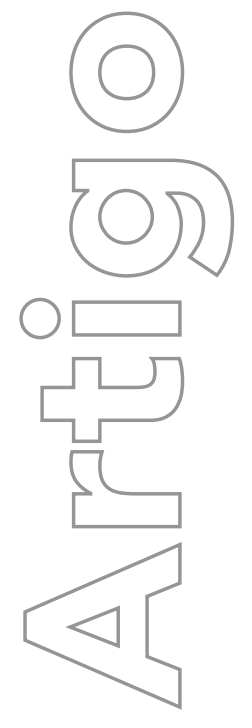

\section{revista}

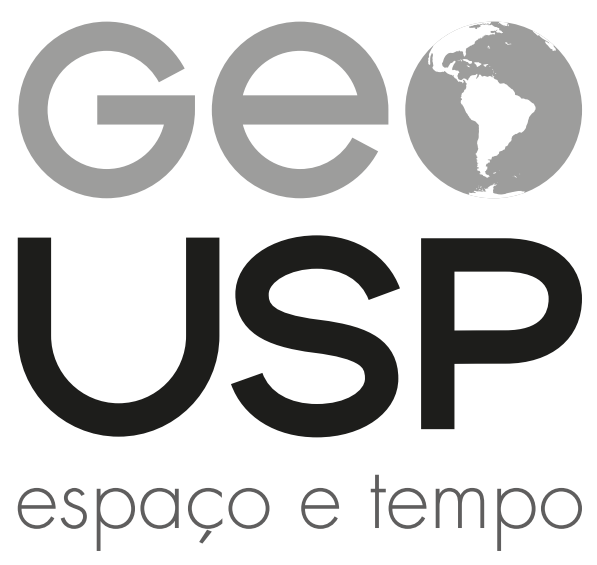

Volume $24 \cdot n^{\circ} 2(2020)$

ISSN 2179-0892

\section{Da construção} socioespacial dos mercados aos avanços da financeirização

\author{
Felipe Nunes Coelho Magalhães \\ Universidade Federal de Minas Gerais, \\ Belo Horizonte, MG, Brasil \\ felmagalhaes@gmail.com \\ (1) 0000-0003-3491-2182
}

p. $279-296$

Como citar este artigo:

MAGALHÃES, F. N. C. Da construção socioespacial dos mercados aos avanços da financeirização. Geousp Espaçoe Tempo(On-line), v. 24, n. 2, p. 279-296, ago. 2020. ISSN 2179-0892.

Disponivel em: https://www.revistas.usp.br/geousp/article/ view/165995. doi: https://doi.org/10.11606/issn.2179-0892. geousp.2020.165995.

\section{(c) $\underset{\mathrm{BY}}{\mathrm{BY}}$}

Este artigo está licenciado sob a Creative Commons Attribution 4.0 Licence 


\title{
Da construção socioespacial dos mercados aos avanços da financeirização'
}

\section{Resumo}

Oartigo pretende contribuir com dois debates atuais no âmbito da geografia econômica: os recentes desenvolvimentos da geografia dos mercados em vertentes que teorizam a centralidade do agenciamento proativo de novos mercados para a expansão capitalista em perspectiva socioespacial buscando reposicionar a categoria na geografia econômica (para além da oposição entre a simples apologia liberal e a simples reprovação por parte da perspectiva crítica), e a discussão teórica da financeirização do espaço, dinâmica fundamental nas relações contemporâneas entre espaço e economia e na reprodução ampliada do sistema econômico vigente. Para agregar ferramentas conceituais ao estudo de dinâmicas contemporâneas de alta relevância para o campo da geografia econômica por meio de pesquisa bibliográfica comentada e incrementada com novas produções, o texto discute também o aprofundamento da financeirização em suas rodadas atuais, ligadas ao extrativismo rentista estendido na direção das economias populares e ao chamado capitalismo de plataformas nas metrópoles.

Palavras-chave: Geografia dos mercados. Construção social dos mercados. Financeirização. Processos socioespaciais contemporâneos.

\section{From the sociospatial construction of markets to the advancements of financialization}

\begin{abstract}
The article proposes contributions to two current debates within the scope of economic geography: the recent developments in the geography of markets, in lineages that theorize the centrality of the proactive formation of new markets for the dynamics of capitalist expansion in sociospatial perspective, seeking to reposition the category in economic geography (beyond the opposition between the simple liberal apology and the simple condemnation from a critical perspective);
\end{abstract}

1 Agradeço ao CNPq pelo financiamento de parte da pesquisa que resultou neste artigo, na modalidade pós-doutorado júnior (PDJ), projeto n. 150129/2018-1. 
and the theoretical discussion about the financialization of space, a fundamental dynamic in the contemporary relations between space and economy and in the expanded reproduction of the current economic system. With the objective of adding conceptual tools for the study of contemporary dynamics of high relevance to the field of economic geography, through commented bibliographic research augmented with new elaborations, the text also addresses the deepening of financialization in its current rounds, related to rentist extraction extended towards popular economies and the so-called platform capitalism in the metropolis.

Keywords: Geography of markets. Social construction of markets. Financialization. Contemporary sociospatial processes.

\section{De la construction socio-spatiale des marchés aux avancées de la financiarisation}

\section{Résumé}

Larticle propose des contributions à deux débats actuels dans le cadre de la géographie économique: les développements récents de la géographie des marchés, dans des lignes qui théorisent la centralité de l'agence proactive de nouveaux marchés pour la dynamique de l'expansion capitaliste dans une perspective sociospatiale, cherchant à repositionner la catégorie en géographie économique (au delá de l'opposition entre la simple apologie libérale et la simple condamnation du point de vue critique); et la discussion théorique sur la financiarisation de l'espace, une dynamique fondamentale dans les relations contemporaines entre espace et économie et dans la reproduction élargie du système économique actuel. Avec l'objectif d'ajouter des outils conceptuels pour l'étude des dynamiques contemporaines de haute pertinence pour le domaine de la géographie économique à travers des recherches bibliographiques commentées et enrichies de nouvelles élaborations, le texte aborde également l'approfondissement de la financiarisation dans ses cycles actuels, liés à l'extraction rentiste étendu aux économies populaires et au soi-disant capitalisme de plate-forme dans les métropoles.

Mots-clés: Géographie des marchés. Construction sociale des marchés. La financiarisation. Processus socio-spatiaux contemporains. 


\section{Introdução}

Trazemos neste ensaio um conjunto de intervenções direcionadas a dois blocos de produção acadêmica em curso no âmbito da geografia econômica, que atravessam temas de grande relevância teórica para o entendimento de dinâmicas contemporâneas em escalas diversas, como: o neoliberalismo em crise persistente, tendo como consequência a redefinição agressiva e autoritária do aparato regulatório (Hendrikse, 2018), como no caso exemplar do Brasil pós-golpe de 2016; ${ }^{2}$ a indicação de retorno do protecionismo e de novos modos de conformar mercados a partir da ação do Estado, em novos padrões de nacionalismo econômico; o crescente recurso a parcerias público-privadas em domínios diversos de atuação do Estado; o provimento da chamada habitação social de mercado como parte fundamental duma guinada mercadológica afinada com o avanço do processo de financeirização na gestão pública e na política urbana, entre muitos outros.

Com o objetivo de agregar ferramentas conceituais para o estudo de dinâmicas contemporâneas de alta relevância para o campo da geografia econômica, o texto é dividido em duas seções, correspondentes às abordagens exploradas: a primeira diz respeito à nova geografia econômica dos mercados, vertente que busca reposicionar a categoria na perspectiva crítica (para além da oposição entre a simples apologia e a simples condenação); e a segunda parte trata da produção contemporânea de novas camadas no processo de financeirização do espaço, fundamental tanto no âmbito das relações contemporâneas entre espaço e economia em escalas múltiplas quanto na reconfiguração dos aparatos hegemônicos de reprodução ampliada do sistema econômico vigente - que envolve o avanço da hegemonia das finanças na direção de sua penetração em setores econômicos diversos e sua crescente capilarização no espaço e na sociedade (ao lado da generalização da própria industrialização para além do setor secundário no período fordista-keynesiano, que implicava também a produção do espaço em termos industriais). Em termos de metodologia, o recorte analítico apresentado baseou-se na interlocução entre as fontes secundárias apresentadas, tendo em vista uma territorialidade transescalar das relações da realidade brasileira com o cenário internacional atual.

\section{Novas geografias dos mercados}

Kojin Karatani (2014) propõe um reposicionamento crítico do enfoque sobre o modo de produção predominante no estudo da história econômica na direção do que denomina modo de trocas: o formato que tomam a circulação e a distribuição de recursos em determinado sistema econômico. Karatani trabalha uma sequência histórica de quatro modos de intercâmbio como formas de organização econômica da sociedade: (a) a reciprocidade e a dádiva (como em Marcel Mauss) dos povos seminômades que sobrevive em parte nos grupos indígenas e populações tradicionais atuais, (b) a autoridade e proteção/centralização e distribuição na gênese dos impérios pós 3500 a.C., que sobrevive no Estado moderno, (c) o sistema baseado em troca de mercadorias, no consentimento mútuo (mas não na igualdade mútua), que conforma o mercado e termina por redefinir o próprio modo de produção em função de suas dinâmicas, e (d) um porvir que promove o retorno dialético à reciprocidade inicial, em novos formatos.

2 Para uma perspectiva socioespacial da ruptura institucional do impeachment de 2016, ver Magalhães (2019). 
Nessa mesma esteira, consideramos que: a ênfase crítica na produção relegou as trocas a um espaço secundário, sendo um terreno de dinâmicas com consequências socioespaciais decisivas; e a ênfase no mercado não é necessariamente um movimento analítico liberal, que deixa de reconhecer a exploração do trabalho na produção como um processo primordial no sistema econômico hegemônico, mas enxerga esse próprio tempo-lugar do trabalho como resultado de um processo de mercado - como na própria leitura marxiana original, só ocorre em função da conformação de um mercado específico: o mercado de trabalho, onde a força de trabalho é comprada e vendida por determinado preço. Esse processo só é possibilitado por uma dinâmica proativa de construção e reprodução histórica e socioespacial das condições para que este mercado exista.

Dan Cohen (2017) apresenta um panorama da literatura recente em torno do estudo geográfico dos mercados baseado num retorno à ideia de Karl Polanyi de que tradicionalmente o mercado foi abordado na ciência social por meio de uma polarização entre a visão liberal da perfeição do livre mercado como ente capaz de resolver problemas da sociedade por seus próprios mecanismos internos, e a visão marxista da condenação do mercado como o lugar da exploração e da espoliação, sendo seus formatos pouco importantes em relação às leis coercitivas da competição e seus efeitos nocivos. A proposta defende que ambas perspectivas atrapalham o estudo cuidadoso dos mercados ao criarem noções apriorísticas e preconcebidas a respeito de seu funcionamento e seus efeitos, que não somente são mais complexos, variados e nuançados do que essas narrativas permitem assumir, mas ocupam posições muito significativas na geração de processos socioespaciais diversos para ser tratados de forma pouco rigorosa em relação à pesquisa e à teorização sensíveis às diferenciações historicamente constituídas em cada lugar e circunstância.

Trata-se de fazer com que "as geografias dos mercados [conectem] sua micropolítica às macroestruturas do capitalismo, e deste modo [possam] abrir novos entendimentos acerca do papel do espaço e do lugar no funcionamento deles" (Cohen, 2017, p. 2). No deflagrar da crise financeira de 2008 (cujas consequências permanecem em cena de muitas formas em todo o mundo), chama atenção a incoerência entre a importância central de aspectos específicos dos mercados de futuros e derivativos atrelados a imóveis e o fato de esses mecanismos permanecem em grande medida incompreendidos por muitos pesquisadores, mesmo aqueles mais dedicados a questões relativas à dinâmica capitalista e seus efeitos no espaço. Cohen entende que as implicações dessa contradição teriam tido papel importante na emergência recente da geografia dos mercados que busca analisar.

De fato, a própria crise é deflagrada pela operação de mercados específicos no setor financeiro, que só puderam ganhar terreno a partir da construção das condições para sua própria existência, o que é realizado por um processo regulatório complexo e envolve uma geografia específica: de seus agentes, das instituições envolvidas e de suas inúmeras implicações. Trata-se das chamadas inovações financeiras criadas pelo próprio setor a partir da dinâmica de desregulamentação que ele atravessa nos principais centros do sistema financeiro internacional a partir da década de 1980, que faz surgirem derivativos, mercados de opções e mecanismos criadores de novos títulos financeiros compostos de elementos diversos à enésima potência. O subprime, principal gatilho da crise, é justamente um desses elementos, surgidos num processo de criação 
de mercados por meio de dinâmicas institucionais de transformação do aparato regulatório, em que o fator corrupção não deixa de ter um papel central no agenciamento que permite a decolagem da securitização de hipotecas "podres" pela atuação enviesada das agências de risco e dos próprios agentes financeiros vendendo títulos de altíssimo risco como se não o fossem.

A dinâmica geográfica urbana relativa à crise não é um elemento menor, seja por suas causas - mercado imobiliário sobreaquecido gerando forte gentrificação e intensificando a suburbanização - ou por seus efeitos: dos despejos de hipotecários inadimplentes aos processos atuais relativos às cidades em regime de austeridade fiscal (ver, por exemplo, Peck e Whiteside, 2016), que, por sua vez, também constitui um regime regulatório altamente favorável ao surgimento de mercados e ao crescimento de mercados existentes.

Um dos efeitos do enfoque teórico-metodológico nos mercados foi a abertura de uma agenda de pesquisa para entender como eles são produzidos de forma proativa, por uma combinação ampliada de agentes, que vão de agenciadores e detentores de capitais privados, agências não governamentais diversas e o Estado em inúmeras frentes de atuação. Há assim um processo social (inerentemente político) por trás do aparecimento, da reprodução e do declínio de mercados específicos conformados por agentes específicos e no qual participa outro conjunto de setores, com sobreposições importantes entre si. Duas interpretações sociológicas se relacionam a essa perspectiva: a noção do construtivismo social, que aplicada aos mercados estudaria como se constroem socialmente, a partir de relações sociais previamente estabelecidas, engendrando novas relações sociais a partir de sua construção; e a ideia, intimamente relacionada a essa, do caráter contingenciado do processo de construção e transformação de mercados: são dinâmicas contidas em redes e instituições, constituídas a partir de suas configurações cambiantes e dos agentes que as compõem.

Há aí uma ideia de que tanto na visão neoclássica quanto no marxismo tradicional, os mercados são naturalizados (para bem e para mal), tratados como dados, e portanto raramente estudados nos processos que dizem respeito a suas constituições e transformações: uma ampla agenda de pesquisa que envolve instituições de tipos os mais diversos (de órgãos públicos a entidades de classe ou sindicatos), movimentos sociais não institucionalizados, e grupos sociais específicos - que podem ser identificados por um critério de classe ou por outras formas diversas. A dimensão escalar e/ou regional é fundamental para entender esses processos, que são sempre relativos a transformações socioespaciais diferenciadas no território e constitutivas de dependências da trajetória específicas do lugar e da região (Storper, 1997).

A configuração do mercado imobiliário em determinado país, região ou cidade, por exemplo, envolve uma institucionalidade regulatória que precisa ser constituída para que se concretizem as transações de compra e venda e cujas especificidades são fundamentais nas suas dinâmicas, que por sua vez geram efeitos socioespaciais significativos. Trazendo exemplos da realidade urbana/metropolitana brasileira: o crescimento das favelas e dos loteamentos irregulares em função da incapacidade do Banco Nacional da Habitação (BNH) para atender às camadas de renda mais baixa na década de 1970; a reprodução de um enorme estoque de moradias vazias no contexto atual, que concorre para a continuidade da pressão pela periferização, por meio da expulsão da população de baixa renda de regiões em processo de valorização fundiária; entre 
inúmeras outras dinâmicas. Trata-se de um mercado cujo funcionamento atravessa movimentos de oferta e demanda (que também são historicamente baseados em pilares jurídicos e políticos), mas cujos aspectos institucionais/regulatórios são centrais tanto em suas características quanto nos efeitos que ele gera para além de seu próprio domínio de atuação - ou seja, na cidade, no território, na região. ${ }^{3}$ Assim, um determinado mercado depende de certa configuração de um agenciamento que o contingenciará - disponibilidade de mão de obra, de acesso aos recursos naturais, de um aparato jurídico consolidado que defina contratos, propriedade, moeda, relações trabalhistas, relações financeiras etc., de diversos aspectos infraestruturais, entre outros elementos daquilo que a economia política urbana de Jean Lojkine (1981) chamou de "condições gerais de produção", " aqui relacionadas a condições que regem a conformação de mercados. E obviamente, os agentes operadores dos agenciamentos de acumulação de capitais em determinado mercado procuram interferir direta ou indiretamente no domínio regulatório-institucional da conformação dos mercados onde atuam ou atuarão. Essa dinâmica tem um aspecto socioespacial central e só pode ser compreendida em profundidade de perspectivas que atravessem sua dimensão geográfica: o próprio espaço produzido é imprescindível na conformação das condições gerais colocadas acima, bem como a dimensão regional desses processos, que transformam regiões ao mesmo tempo em que são condicionados por elas, mas sem nunca deixar de atravessar processos de natureza transescalar.

Outra implicação dessa perspectiva é que, numa sociedade regida por uma forma política de organização do Estado baseada na ideia de que o livre mercado é o formato mais adequado para canalizar soluções para demandas coletivas diversas, a formação de novos mercados torna-se central nessa dinâmica social, e ela não ocorre sem a própria atuação das instituições necessárias para tal: por meio de parcerias público-privadas, do provimento de um enquadramento jurídico necessário à expansão de determinados setores, ou de forma indireta, pela própria retirada do Estado provedor de serviços coletivos de determinadas áreas de atuação para que novos mercados sejam criados em torno da oferta daqueles serviços: saúde, educação, transporte e moradia (e, mais recentemente, o saneamento). As características (tamanho, alcance, formato dos serviços prestados, preços praticados, mercados consumidores atendidos, grupos excluídos desse atendimento) da oferta privada desses serviços hoje é, em grande medida, uma função inversa da ação direta do Estado em seu provimento: se saúde, educação e transportes públicos fossem universalmente oferecidos em padrões qualitativos elevados, esses mercados seriam uma fração de suas dimensões atuais.

E aqui há um ponto delicado quanto à tradição de maior adesão à teorização crítica da dinâmica econômica: muitas vezes essas dinâmicas de conformação de mercados são anteriores e condicionam diretamente as condições dos processos produtivos em si, tradicionalmente tomados como o enfoque principal da teorização crítica, por serem o espaço-tempo da produção

3 Para inúmeros exemplos concretos de pesquisas empíricas recentes no contexto internacional em torno desses processos, ver Cohen (2017).

4 A partir da definição marxista dessas condições como infraestrutura básica de acumulação (como transportes e comunicações), Lojkine (1981) adapta a noção de "condições gerais de produção" para o período fordista-keynesiano, quando os equipamentos coletivos e as instituições (geralmente estatais, em função da baixa lucratividade do provimento desses atributos infraestruturais naquele contexto regulatório) concentram-se em áreas urbanas adensadas e envolvem elementos mais complexos de apoio à atividade industrial. 
de valor, logo, da extração de mais-valor, da exploração do trabalho remunerado apenas parcialmente por sua atividade produtiva. Mesmo no processo histórico clássico da revolução industrial inglesa, é muito comum e frequente a suposição de um arquétipo sociológico geo-historicamente míope, que não reconhece a centralidade do imperialismo mercante inglês, da conformação de mercados a partir dos controles de rotas marítimas e do processo colonial, sobretudo na Índia, e em segundo plano na própria América Latina do século XIX, que garantem demanda para a decolagem industrial britânica (Hobsbawm, 1968).

Nesse sentido, a conformação de fluxos na conquista de monopólios de rotas marítimas comerciais por meios militares é tão fundamental quanto os processos que ocorrem nas duas extremidades geográficas das rotas: a colonização garantidora de mercados e recursos naturais numa ponta e, na outra, a produção em si. Trata-se, assim, de um agenciamento, conjunto de elementos interligados e interdependentes que se influenciam mutuamente e passam por transformações constantes, sem que haja primazia absoluta e constante por parte de determinado componente específico. Nessa perspectiva, os fluxos não são secundários e muito menos espontâneos: precisam ser constituídos ativamente, por processos, agentes e redes, intrinsecamente atravessados por nexos políticos e que, no caso específico do comércio internacional, são marcados por um teor conflitivo/militar que não estaria presente se essa conformação fosse secundária na estratégia de fortalecimento de determinada ordem hegemônica pelo crescimento da indústria.

Quanto ao discurso em defesa do livre mercado e voltando à crise de 2008, é interessante notar como ela expõe a nudez do rei ao demonstrar, pela ação do Estado salvando os bancos diretamente, a falácia do discurso da autorregulação eficiente, embora o constante recurso da economia ortodoxa à noção de falhas de mercado 5 não deixasse de ser constantemente acionado naquele episódio. No entanto e além disso, revelou-se a dependência direta que a própria existência dos mercados que entraram em colapso na crise tinham das instituições para funcionar. Ou seja, além de os mercados de derivativos precisarem ser ativamente criados, a dependência das instituições diz respeito tanto ao pacote de resgate dos bancos por parte do Estado quanto a uma configuração básica que dá condições de existência aos próprios mercados no domínio jurídico-institucional e regulatório. $\bigcirc$ corolário-oxímoro aqui é que mercados perfeitos requerem configurações jurídico-institucionais perfeitas: obviamente, do ponto de vista das necessidades e objetivos dos próprios mercados. $\bigcirc$ que necessariamente não ocorrerá sem o atravessamento pelo terreno da política, cabendo avaliações acerca do quão democrático é o caráter dessas conformações, bem como das interações e embates ligados a seus processos de institucionalização.

A perspectiva de Berndt e Boeckler (2009, 2011, 2013) aponta também a contribuição do trabalho de Michel Callon (1998), a partir da aplicação das contribuições de Bruno Latour (2012) e sua teoria do ator-rede para o âmbito da economia, entendida como um universo em grande medida fabricado pela própria ciência econômica. Se os mercados são institucionalmente definidos, o formato de ação empreendido nessas construções é instruído por um teor analítico-discursivo (que se apresenta como científico) produzido por uma tradição epistemológica específica - num interessante paralelo com a leitura de Thompson (1998) de que o advento do livre

5 Situações excepcionais que, de acordo com a teorização neoclássica, justificam a ação do Estado na correção de resultados negativos que podem advir da não intervenção. 
mercado é resultado da incorporação do liberalismo (em Locke e Smith, sobretudo) na própria ação do Estado.

Há aí um risco das abordagens a respeito da conformação de mercados específicos deixarem de lado a necessidade de manter em vista uma perspectiva transescalar que permita entender sua inserção em agenciamentos maiores. Como colocado acima, essas montagens maiores são fundamentais para a compreensão da importância dos mercados, que por sua vez não deve ser levada ao ponto de se proporem enfoques muito recortados em seus processos e que deixem de enxergar o conjunto em que se inserem. Cohen (2017) aponta o trabalho de Braun (2016), dedicado a encontrar e teorizar ligações entre estruturas e processos em escalas mais restritas (como a conformação de mercados específicos em localidades/regiões específicas) à dinâmica capitalista em escala maior - o que requer abordagens abertas à perspectiva da transescalaridade: a interação entre escalas, a constituição interdependente entre elas e entre processos situados em escalas distintas, a necessidade de transitar as perspectivas entre escalas múltiplas (e não apenas o local e o global, em termos simplistas, automatizados e alheios a preocupações empíricas). Essa é justamente a falha principal nos projetos que seguem as contribuições de Bruno Latour: não há espaço para essa dimensão transescalar nas teorizações que descartam praticamente de antemão qualquer movimentação analítica que possa ser vista como um sobrevoo distante do nível etnográfico de entendimento do mundo e suas transformações (absolutamente indispensável e ao mesmo tempo insuficiente; sem deixar de considerar que se poderia dizer exatamente o mesmo sobre a economia política).

Talvez a avaliação mais interessante de Cohen (2017, p. 9-14) seja a leitura dos mercados como sítios de disputa. Um primeiro exemplo das enormes implicações dessa perspectiva: a própria conformação de um mercado de trabalho - fator essencial para o trabalho em si, como única fonte de valor possível, e para sua subsunção a agenciamentos produtivos heterônomos, em que ele não mais tem controle sobre os frutos de si mesmo - é a restrição do acesso ao mercado entendido de forma ampliada por parte daqueles que se tornam trabalhadores, além dos próprios meios de produção, mais tradicionalmente enfatizados. $\bigcirc$ controle e a restrição do acesso aos mercados é parte importante do leque de condições que os agentes hegemônicos devem construir para garantir certo fluxo da oferta de trabalho em baixos custos para as atividades produtivas que controlam.

Esse aspecto nos permite a passagem a outra forma que a ênfase nos mercados vem ganhando na literatura recente em geografia econômica, que é a inspiração direta em Karl Polanyi (1980[1944], 2012[1977]; Peck, 2013). Essas abordagens se assentam sobre dois pilares da obra de Polanyi. Em primeiro lugar, a proposta daquele autor de que o capitalismo se fundamenta na transformação da terra, do trabalho e da moeda em mercadoria, que seriam mercadorias fictícias, pois não se tratam de bens ou serviços produzidos para o mercado, mas que este cria a capacidade de atrair e inserir em sua lógica de trocas. Em segundo lugar está a ideia do duplo movimento como uma caracterização ampliada da história econômica desde a revolução industrial, em que o mercado produz num primeiro período a tensão social, o desmantelamento de relações comunitárias, e uma situação de crise social em função da primazia das mercadorias fictícias, que só não faz com que o próprio sistema econômico entre em colapso em função do 
segundo movimento, de ampliação de direitos, de construção de mecanismos de compensação das dinâmicas de mercado.

Trata-se, obviamente, de uma visão que é produto de seu tempo, no imediato pós-guerra, marcado pelo quase-consenso em torno do pacto fordista e o início da ampliação da experiência do Estado de bem-estar social pelo mundo ocidental/do norte global. No entanto, esses dois cabedais teóricos tornam-se, nas abordagens contemporâneas, ferramentas de pesquisa regional empírica acerca da dinâmica capitalista do espaço, caracterizando-se muitas vezes por escalas menores do duplo movimento e da conformação, ou do restabelecimento, das condições em que as mercadorias fictícias são ofertadas no mercado. $\bigcirc$ reajuste regulatório pós-golpe de 2016 no Brasil provê um riquíssimo terreno para abordagens institucionalistas e regulatórias ligadas a estas abordagens, pois atua justamente num retorno ao primeiro movimento da dinâmica acima, e no restabelecimento dos termos de funcionamento do mercado de terras (nova legislação da regularização fundiária, tentativas de anistiar terras griladas) e do mercado de trabalho (reforma trabalhista), forçando uma reestruturação produtiva antidemocrática em função da derrocada do mercado internacional de commodities, em 2014, que sustentava o modelo regulatório anterior.

Além desses dois pilares, a contribuição de Polanyi nessa agenda de pesquisa é seu potente esclarecimento para que se entenda o econômico como processo instituído e suas implicações profundas, mas também à necessidade de se diferenciarem e separarem, teórica e historicamente, os mercados do capitalismo ou do sistema econômico como um todo, que envolve outros modos de integração e outros tipos de relação entre subsistência, reprodução e esfera produtiva.

\section{Atualização contemporânea da financeirização do espaço e da urbanização}

O enfoque nos mercados como construções sociopolíticas que são proativamente agenciadas nos revela que, no capitalismo contemporâneo, de forma concomitante e relacionada à reorganização do mercado de trabalho e de terras, a expansão do terreno de atuação das finanças ocupa lugar primordial na construção de mercados diversos. Nessa análise crítica, a geografia econômica tem papel fundamental na compreensão da primazia do setor financeiro no capitalismo contemporâneo. De forma esquemática e introdutória, trata-se de uma dinâmica histórica relacionada ao avanço do neoliberalismo, que envolve a manutenção, desde o início da década de 1980, da impossibilidade do gasto contracíclico keynesiano, pela mesma lógica que subordina os Estados aos credores.

O setor financeiro concentra esses agentes credores dos Estados endividados, que, a partir da abertura de fronteiras ao livre fluxo internacional de capitais, ganham ainda maior poder de influência com a ameaça da fuga de capitais como instrumento de imposição antidemocrática de políticas e reformas. Esse agrupamento de agentes é abastecido por um amplo leque de capitais advindos de fontes diversas, sendo capaz de aplicar estes montantes se inserindo em mecanismos de acumulação (D-M-D') que também são difusos e diversos. Ou seja, são operadores de fluxos com capacidade de entrada e saída de investimentos diversos - de alternar entre fontes diversas com agilidade crescente. Neste contexto de fluidez aumentada, a indústria torna-se excessivamente rígida e presa a suas próprias estruturas produtivas, criando a capacidade de direcionar 
investimentos para um leque aberto de plataformas de acumulação a partir do fortalecimento de seus próprios braços financeiros - se sua própria capacidade de valorização de capitais estiver enfraquecida, investe-se em outras plataformas de acumulação (títulos de dívida pública, fundos de investimento diversos, imóveis etc.).

setor financeiro torna-se capaz de controlar e comandar dinâmicas econômicas diversas, e o antigo conflito entre capital produtivo (indústria) e capital fundiário rentista (grandes proprietários de terra e imóveis) se enfraquece na medida em que o setor financeiro passa a comandá-los a ambos e se interessa em abrir boas oportunidades de lucratividade nos dois terrenos, o que concorre para enfraquecer políticas públicas voltadas ao controle da renda da terra em contextos regulatórios diversos. Assim, as consequências socioespaciais também são significativas, levando a um aumento da especulação imobiliária e dos processos de gentrificação, a maiores pressões sobre áreas rurais de posseiros, indígenas, quilombolas e outros sem segurança de propriedade ou posse, e, ao fim e ao cabo, à intensificação de conflitos socioespaciais diversos.

Na escala nacional, em que operam instituições de maior envergadura e alcance na reprodução do aparato regulatório que estrutura a própria acumulação, a disputa em torno das reformas na conjuntura pós-golpe de 2016 e o recrudescimento ainda maior do projeto instalado em 2019 envolvem uma clara lógica de abertura de novas frentes para a penetração de capitais financeiros. Diretamente, na reforma da previdência, lançando um enorme fluxo de poupança em direção aos bancos privados, no ataque ao ensino público como abertura de mercados para os capitais atuantes na oferta privada do serviço (indiretamente, aumentando a demanda de financiamento estudantil) e na abertura de uma enorme frente de investimento imobiliário em potencial, tanto na cidade quanto no campo, pela nova lei da regularização fundiária, entre outros (Magalhães, 2019). E indiretamente, pela abertura de amplos territórios para a penetração de capitais dos setores extrativistas nas regiões Norte e Centro-Oeste do Brasil, pela reconfiguração dos territórios indígenas somada à carta branca ao desmatamento, que amplia o campo de atuação dos setores extrativistas e o rentismo das terras abertas tornadas ativos financeiros em potencial. Trata-se de um nexo de abertura incessante de novas frentes para a captura de renda do espaço social, que, na atualidade, como indicaremos abaixo, já apresenta camadas adicionais importantes em relação àquelas mapeadas por Sanfelici (2013).

Portanto, há uma entrada importante dos processos de financeirização na construção proativa de mercados onde atuarão de forma privilegiada. $\bigcirc$ que não ocorre sem o engajamento violento na disputa pelo aparato regulatório e em todo o arcabouço legal e institucional que provê bases jurídicas para os modos de operação e funcionamento da esfera da acumulação. Como já apontado acima e demonstrado detalhadamente por Durand (2017, p. 33-37), as "inovações financeiras" na criação dos mercados de derivativos securitização financeiros, responsáveis em grande medida pela crise financeira de 2008, foram produto de intenso trabalho de agentes do próprio setor, muitos dos quais vinculados ao antigo mercado de futuros de Chicago (Chicago Board of Trade, criado em 1848 para compra e venda de derivativos de produtos agropecuários), por meio de uma atuação centrada na alteração do aparato regulatório voltada para o setor, com o apoio direto do alto establishment da ciência econômica que passava a ocupar sua corrente 
principal já na década de 1970, representada pela escola monetarista de Chicago e a figura emblemática do professor Milton Friedman, que dava seu aval a inovações financeiras irrestritas:

A comunidade acadêmica da ciência econômica forneceu justificativas decisivamente importantes para a criação de mercados de derivativos. Mas não conseguiu isso sozinha. Seria necessário um contexto que daria sentido a esta construção (o desmantelamento do sistema monetário de Bretton Woods) e, posteriormente, uma atividade empreendida coletivamente. Os motivos das pessoas que se mobilizaram para criar o mercado de derivativos não corresponderam àqueles de homines oeconomici estritamente racionais e regidos por interesses próprios. Seus motivos foram construídos por meio de uma comunidade na qual interações diretas e repetidas permitiram simultaneamente a cooperação e a punição daqueles que tentaram se isolar dessa comunidade (Durand, 2017, p. 36-37).

A partir de Durand (2017), ${ }^{6}$ vemos também como o padrão da desregulação do setor um modo de construção de mercados a partir da atuação proativa no âmbito da política - envolve alguns aspectos específicos que são chave na deflagração da crise de 2008: a possibilidade da securitização de títulos podres (o subprime), e a não necessidade de capitalização por parte dos bancos para dar cobertura ao risco aumentado das operações que as inovações financeiras (dos derivativos e da securitização) envolviam. Ou seja, há uma transferência do risco para o próprio setor público na figura dos bancos centrais como garantidores em última instância da solvência das instituições bancárias, que é justamente o fator que entra em cena no momento em que os bancos não conseguem se salvar com as próprias pernas - configurando aí uma socialização das perdas e dos riscos que acompanha a apropriação privada de seus (enormes) ganhos.

A relação da proeminência histórica do setor financeiro com sua capacidade cada vez mais aprofundada e de alcance progressivamente estendido para criar, manipular e gerir mercados em benefício próprio passa em grande medida pela questão do poder de mercado das grandes corporações, que, por combinações variadas de acesso à tecnologia e às finanças, tornam-se mais ou menos inseridas em estruturas de mercado monopolistas ou em formações oligopolistas. Esse é um fator surpreendentemente ausente na teorização marxiana contemporânea em torno da crise do valor, ${ }^{7}$ que propõe um retorno analítico ao nexo da composição orgânica do capital atingindo níveis de saturação da capacidade extrativa de valor do trabalho por parte dos controladores da produção, apontando ligações dessa suposta crise de lucratividade com os impasses contemporâneos do neoliberalismo. Perde-se de vista o fato de que o poder de mercado exercido por capitais ultraconcentrados, que passam longe de estar expostos a condições concorrenciais, torna-se fonte de lucros exorbitantes, mesmo que a composição orgânica dos capitais aplicados na produção esteja de fato em patamares historicamente elevados.

De fato, as porções das cadeias produtivas globais que executam a própria produção passam a ser subordinadas por agenciamentos ampliados de capitais e mecanismos de acumulação

6 Que nos fornece uma bateria de dados e análises quantitativas cuja reprodução ou apresentação análoga para o contexto brasileiro ultrapassaria o escopo deste artigo.

7 Em Moishe Postone ou Robert Kurz, por exemplo. Para uma sistematização do ponto de vista da geografia e inserida num notável panorama crítico da condição periférica contemporânea, ver Cannetieri (2019, p. 14-18). 
e circulação onde entram na ponta oposta do setor financeiro, ou seja, nas porções heterônomas dos subcontratados responsáveis pela "mera produção". Os detentores de patentes, que são operadores das marcas, do design, do marketing e da comercialização, ganham um quase-monopsônio de uma rede de fornecedores que inclui os responsáveis pela própria produção, e passam também por relações de subordinação, ao comando e controle do próprio setor financeiro que insere e retira capitais de seus modos de agenciamento da acumulação. Bancos sustentam formações de mercados monopolistas/oligopolistas fechando o acesso ao crédito e com isso criando barreiras para o surgimento de concorrentes que comprometeriam os lucros das empresas que financiam (Durand, 2017, p. 123).

Portanto, a proeminência do poder de mercado no capitalismo atual passa pela ligação dessas estruturas de geração de sobrelucro com o setor financeiro e envolve formações diversas que (se perdem no foco analítico/crítico centrado na produção e) vão dos grandes varejistas, que abusam de seu poder de mercado na relação com fornecedores, à proeminência crescente do chamado "capitalismo de plataformas" (sendo a Amazon uma combinação dos dois formatos, daí sua pujança).

Esse é um elemento que no contexto atual se vincula diretamente à internet e sua capacidade aglutinadora de processos sociais diversos, cujas enormes consequências ficaram mais claras nos últimos anos, em função do impacto nocivo no processo eleitoral em diversos contextos, sendo o caso brasileiro um dos mais gritantes. As consequências das interações entre metrópole e internet envolvem elementos para toda uma agenda de pesquisa ainda em aberto, sendo o capitalismo de plataformas apenas uma de suas muitas facetas.

A partir de Srnicek (2016), plataformas são estruturas digitais que promovem o encontro entre ofertantes e consumidores em transações únicas e discretas, possibilitando uma intensificação significativa do grau de flexibilização das relações de trabalho, produção e comercialização. Tendem à rápida conformação de monopólios em cada seara específica de atividade em que penetram, em função da força do efeito formação de rede, que torna os usuários demandantes presos às plataformas que concentram ofertantes e vice-versa. No caso das redes sociais, a tendência ao monopólio vem do fato de que os usuários ficam presos ao provedor que, passa a concentrar as redes de conexões fixadas em sua plataforma, sendo estas redes constituem justamente o valor de uso mobilizado pelos usuários, e a extração de valor ocorre pela obtenção (e revenda) de informações pessoais em enorme escala, somada à comercialização dos espaços de publicidade e propaganda adjacente aos conteúdos produzidos pelos próprios usuários - num nexo de extração de valor da atenção e do uso que, do ponto de vista do usuário, é aparentemente gratuito, análogo à publicidade na televisão e no rádio, com a diferença de que a geração de conteúdo é terceirizada ao trabalho não remunerado dos próprios espectadores.

As implicações desse capitalismo de plataformas na extração de renda e mais-valor de forma flexível e difusa no tecido socioespacial são expressivas, e seus agenciamentos têm na metrópole um catalisador fundamental, pelo fato de ela constituir uma enorme concentração de fatores que podem ser combinados de diferentes formas, de acordo com demandas que podem ser efêmeras, específicas e variadas - mas sempre por um nexo de captura e canalização de mais-valor e renda - sendo que a concentração de mercado (e consequentemente de capitais) é 
fundamental na constituição desse circuito e em suas relações socioespaciais. Nisso, a metrópole se transforma de plataforma socioespacial para a acumulação industrial em plataforma para a acumulação baseada em arranjos flexíveis diversos de produção, comercialização e consumo. O que não ocorre sem a continuada acumulação primitiva que torna os fatores disponíveis ao trabalho e ao aluguel, combinada com a reiterada desigualdade herdada que cria as assimetrias que caracterizam as entradas (e saídas) por portas distintas nesses arranjos flexíveis.

É desse modo que, do ponto de vista da penetração das finanças no tecido socioespacial, as plataformas tornam-se complementares ao próprio mercado imobiliário, mecanismo central na mobilização da renda e do mais-valor por parte do setor financeiro em sua lógica de sucção e extração de fluxos econômicos de uma base socioespacial ampliada na direção da remuneração dos capitais que ele agencia. Em Hardt e Negri (2016[2009]), a metrópole centrada no trabalho biopolítico (aquele que tende à equivalência com a própria vida, que envolve a produção de emoções, subjetividades, conhecimento e relações), e no capitalismo cognitivo constituído por essa forma de trabalho, torna a geração de valor difundida em seu território, tendendo à equivalência e à mesclagem completa entre as espacialidades (próprias da metrópole do trabalho industrial) do trabalho/da produção e da reprodução.

Na lógica da territorialização difusa do trabalho gerador de valor, que no limite torna-se inseparável da própria vida na cidade, as formas de captura do mais-valor não ocorrem mais de modo restrito ao ambiente interno e bem delineado da produção, precisando se atualizar para que consigam continuar exercendo a exploração do trabalho. Esta continua se baseando na expropriação do comum gerado na esfera da reprodução, mas em novos termos, já que o próprio trabalho biopolítico é efeito direto deste comum produtor dos insumos principais do capitalismo cognitivo: conhecimentos, informação, subjetividades e cultura. É nesse sentido que Hardt e Negri (2016[2009]) propõem que, da mesma forma que a fábrica gera lucro, a metrópole gera renda, "que vem a ser o único meio de o capital capturar a riqueza criada de maneira autônoma".

A ligação inerente e intensa entre capitais imobiliários rentistas e o setor financeiro (advinda das necessidades ampliadas de financiamento do setor imobiliário tanto na ponta da produção quanto no consumo) estende essa relação entre o imobiliário e a captura de valor do trabalho difuso na metrópole às finanças, constituindo canais de extração de valor e renda da base ampliada e difusa em setores diversos de atividade que passam pela renda agenciada pelo imobiliário e culminam no setor financeiro. É neste nexo da canalização de valor e renda duma base ampliada e espacialmente difusa de trabalho e produção que entra, como uma camada complementar, o capitalismo de plataformas na metrópole contemporânea. E é nesse sentido, da base da produção e do trabalho ser constituída por um comum urbano (Tonucci, 2017), ou por aquilo que Topalov (1979) tratou como o "valor de uso complexo" da cidade, é que a extração de valor exercida por essa nova camada constitui um formato de extrativismo do espaço social metropolitano semelhante à indústria extrativa e sua relação com os recursos da terra e da natureza. Assim como na cidade industrial (ou na metrópole fordista-keynesiana), há um processo de "espoliação urbana" - como nos termos clássicos de Kowarick (1979) - diretamente relacionado e proporcional ao próprio trabalho espoliado, que é parte constituinte da disponibilidade de mão 
de obra para as plataformas, que extraem valor do espaço social espoliado contribuindo com a reprodução de sua espoliação em novos termos (flexíveis, pós-fordistas etc.).

A metrópole não produz somente economias de aglomeração para agentes econômicos que se beneficiam de suas vantagens locacionais. Também produz mercados, potencialmente de formas múltiplas, mas tendo essa diversidade reduzida em função da necessidade do controle político do próprio fazer mercados por parte de agentes hegemônicos. Nesta espacialidade, o capitalismo de plataformas conduz um salto na extração de renda do valor de uso complexo de um lugar econômico de alta densidade relacional, ainda conduzindo excedentes para operadores situados no norte do mundo (como no urbano fordista semiperiférico).

Ao terceirizar o custo fixo para os próprios trabalhadores, geram uma renovação em larga escala de velhas práticas de constituição de mercados de trabalho, no vínculo entre "uberização" e a tradição do boia-fria, ideologizada pelas subjetividades do empreendedorismo. Ademais, gera-se um mercado de crédito novo, do financiamento do próprio custo fixo, e a extração de renda ocorre numa relação com o valor coletivo do lugar paralelo ao rentismo tradicional da terra, mas agenciando encontros da oferta com a demanda (ou seja, mercados) pela operação monopolista das plataformas. Em suas novíssimas rodadas, a uberização promove uma apropriação privada e um agenciamento comercial do uso da rua em que dispositivos móveis (bicicletas, patinetes) se apropriam, sem maiores entraves, do espaço público de uso gratuito, em total contraste com a violenta repressão sofrida pela economia popular que busca se estabelecer nas mesmas espacialidades e territorializações do valor de uso complexo da metrópole. ${ }^{8}$

Gago e Mezzadra (2015, p. 43-44) propõem a noção de extrativismo expandido para abordar as relações entre as finanças e as economias populares como uma extensão do nexo extrativista-rentista mais comumente encontrado nos setores primário-exportadores e na exploração da renda da terra em frentes diversas, identificando uma ampla extração de valor e renda também no domínio do trabalho/consumo informal/popular. Para os autores, esse conceito ampliado de extração teria três características marcantes: (1) a extração não se limita a matérias inertes, expandindo-se na direção do trabalho e da cooperação social que permite sua reprodução, (2) a relação extrativa entre capital e trabalho não implica o controle ou o agenciamento direto, como no espaço da produção fabril, mas envolve relações indiretas e um nexo de exterioridade da cooperação dos sujeitos que dá sustento social ao trabalho, e (3) o extrativismo não se associa unilateralmente ao rural ou ao não urbano e precisa ser concebido inclusive em suas relações com o dinamismo urbano das periferias das grandes cidades latino-americanas. Em Gago (2014), a penetração das subjetividades neoliberais nas práticas populares geram hibridizações complexas entre exploração, competição e solidariedade, muito visíveis no mercado imobiliário informal, no comércio popular em feiras e ruas etc.

Na escala das economias urbanas, este circuito popular busca participar do mesmo valor de uso complexo (que hoje passam a ser, cada vez mais, as redes constituídas nos lugares metropolitanos de alta densidade relacional) que o capitalismo de plataformas citado acima, mas ao contrário do que acontece com a expansão marcante destas empresas multinacionais, as práticas

8 Para uma abordagem geográfica da entrada das finanças no circuito das economias populares no período da expansão do consumo pela ampliação da renda de porções da base da pirâmide, ver Silveira (2009). Para um recorte amplo do circuito inferior da cidade de São Paulo no contexto da globalização, Montenegro (2006). 
populares tendem a ser violentamente reprimidas, sobretudo em conjunturas que geram tendências de expansão destas práticas como na crise atual, em que muitas prefeituras de grandes cidades atacam violentamente o crescimento da atividade dos camelôs no espaço público, atuando de forma complementar e em consonância com o reajuste da oferta de mão de obra de baixo custo pela reconfiguração autoritária do aparato regulatório da legislação em escala nacional. Essa é uma manifestação de como o acesso aos mercados, bem como a capacidade de formá-los e colocá-los em prática, são concentrados por agentes econômicos hegemônicos como parte fundamental do exercício e da reprodução de sua dominação e poder.

Apesar das tendências claras de fortalecimento de práticas de "neoliberalismo desde baixo", a possibilidade de constituir mercados se abre a potenciais práticas diferenciais na direção da economia solidária, por exemplo, que tem um potencial de transformação radical a partir do ganho de escala gerado pelo eventual adensamento de suas redes, em que as plataformas eletrônicas podem muito contribuir.

O neoliberalismo em seu estágio atual, pós-crise de 2008, constitui um sistema de governo e ação do Estado vinculado à necessidade de abertura de frentes de oportunidades de investimento em diversos setores e territórios. $O$ setor financeiro se destaca no processo ao reunir em agenciadores únicos (um agente formador de combinações) a capacidade coordenada de se definirem os termos da produção, conformarem e manipularem mercados e de se alterar o aparato regulatório em benefício de seus projetos. Essa habilidade de construir mercados é restrita e constitui uma parte fundamental da composição econômica de determinada hegemonia - os subalternos, que se tornam trabalhadores, são formados por processos múltiplos, que incluem a restrição da possibilidade de eles conformarem seus próprios mercados; ou a manipulação/limitação (pela restrição do acesso à moeda, inclusive) de seus mercados para que eles sejam, quando existirem, mecanismos de reprodução da força de trabalho e de rebaixamento dos próprios salários.

\section{Aberturas: outras economias e mercados além do possível}

Neste artigo, procuramos dar uma contribuição a dois terrenos de pesquisa e teorização da geografia econômica contemporânea, com o intuito de ressaltar sua importância na compreensão de uma série de processos da produção do espaço, sobretudo no âmbito urbano e/ou relativos a urbanização/metropolização. $\bigcirc$ enfoque na formação de mercados e a continuação dessa perspectiva no aprofundamento da atuação e na ampliação do alcance do setor financeiro são potentes elementos explicativos de uma miríade de situações e dinâmicas socioespaciais e políticas contemporâneas, inclusive das violentas restruturações regulatórias em curso, relativas à crise do neoliberalismo e sua consequente guinada autoritária. No entanto, as implicações e aplicações dessas perspectivas - da produção socioespacial dos mercados e do aprofundamento do alcance das finanças nos mecanismos de sucção de renda de uma ampla base geoeconômica - não se relacionam necessariamente a eventos dessa envergadura ou escala, podendo servir como aparato explicativo em espaços econômicos específicos como as parcerias público-privadas, as mudanças em curso do 
aparato regulatório do mercado de terras e mesmo no tráfico de drogas ou nas milícias e em suas redes, em processo de expansão e complexificação.

As implicações políticas do construtivismo social dos mercados são inúmeras. À guisa de conclusão, nos interessa ressaltar que, apesar das restrições estruturais apontadas acima, também são inúmeras - e potentes - as possibilidades de ações emancipatórias no âmbito da performance dos mercados. Trata-se de um agenciamento socioespacial que pode ser transformado para funcionar de outros modos, diferentes do hegemônico "neoliberalismo desde baixo" (Gago, 2014), mesmo no universo da economia popular.

Como acontece no âmbito da economia social e solidária - embora em redes claramente frágeis que acabam limitando muito o alcance das experiências -, não só a produção pode ser feita de outros modos, construindo outras relações e outras formas de criação e mobilização do trabalho, mas também a circulação já se pratica de outras maneiras: em bancos de horas solidárias, sistemas locais de troca ou com moedas ditas sociais, por exemplo, onde prevalecem solidariedade, cooperação e, sobretudo, reciprocidade. As condições (tecnológicas, sociais, urbanas) contemporâneas para a expansão de experiências dessa natureza - na operação de redes ampliadas, diversas, complexas e voltadas para a construção autônoma de economias do comum - se mostram bastante promissoras, mas demandam um esforço coletivo substancial, no qual a presença de elementos conflitivos será proporcional ao incômodo causado à ordem vigente. A ressignificação política dos mercados e a retirada de sua construção do domínio exclusivo dessas hegemonias abre terreno amplo para novas geografias econômicas, com práticas de alteridade que apontam na direção de outras economias e outras produções do espaço.

\section{Referências}

BERNDT, C.; BOECKLER, M. Geographies of markets: materials, morals and monsters in motion. Progress in Human Geography, v. 35, n. 4, p. 559-567, 2011. doi: https:// doi.org/10.1177/0309132510384498.

BERNDT, C.; BOECKLER, M. Geographies of circulation and exchange: constructions of markets. Progress in Human Geography, v. 33, n. 4, p. 535-551, 2009. doi: https:// doi.org/10.1177/0309132509104805.

BOECKLER, M; BERNDT, C. Geographies of circulation and exchange III: the great crisis and marketization "after markets". Progress in Human Geography, v. 37, n. 3, p. 424-432, 2013. doi: https://doi.org/10.1177/0309132512453515.

BRAUN, B. From performativity to political economy: index investing, ETFs and asset manager capitalism. New Political Economy, v. 21, n. 3, p. 257-273, 2016. doi: https://doi.org /10.1080/13563467.2016.1094045.

CALLON, M. Laws of the market. Cambridge: Blackwell, 1998.

CANETTIERI, T. A condição periférica: uma crítica da economia política do espaço em paralaxe. Tese (Doutorado em Geografia) - Instituto de Geociências, Universidade Federal de Minas Gerais, Belo Horizonte, 2019. 
COHEN, D. Between perfection and damnation: the emerging geography of markets. Progress in Human Geography, v. 42, n. 6, p. 898-915, 2017. doi: https://doi. org/10.1177/0309132517729769.

DURAND, C. Fictitious capital: how finance is appropriating our future. London: Verso, 2017. GAGO, V. La razón neoliberal: economías barrocas y pragmática popular. Buenos Aires: Tinta Limón, 2014.

GAGO, V.; MEZZADRA, S. Para una crítica de las operaciones extractivas del capital. Nueva Sociedad, n. 255, enero/feb. 2015.

HARDT, M.; NEGRI, A. Bem-estar comum. Rio de Janeiro: Record, 2016[2009].

HENDRIKSE, R. Neo-illiberalism. Geoforum, v. 95, p. 169-172, 2018. doi: https://doi. org/10.1016/j.geoforum.2018.07.002.

HOBSBAWM, E. Industry and empire. London: Penguin, 1968.

KARATANI, K. The structure of world history: from modes of exchange to modes of production. Durham: Duke University Press, 2014.

KOWARICK, L. A espoliação urbana. Rio de Janeiro: Paz e Terra, 1979.

LATOUR, B. Reagregando o social: uma introdução à teoria do ator-rede. Salvador: Ed. Ufba, 2012.

LOJKINE, J. O Estado capitalista e a questão urbana. São Paulo: Martins Fontes, 1981. MAGALHÃES, F. Postdemocracy reset: Brazil's putschist fix in sociospatial perspective. South Atlantic Quarterly, v. 118, n. 2, p. 401-419, 2019. doi: https://doi. org/10.1215/00382876-7381218.

MONTENEGRO, M. R. O circuito inferior da economia urbana na cidade de São Paulo no período da globalização. Dissertação (Mestrado em Geografia Humana) - Faculdade de Filosofia, Letras e Ciências Humanas, Universidade de São Paulo, São Paulo, 2006.

PECK, J. For Polanyian economic geographies. Environment and Planning A - Economy and Space, v. 45, n. 7, p. 1545-1568, 2013. doi: https://doi.org/10.1068/a45236.

PECK, J.; WHITESIDE, H. Financializing Detroit. Economic Geography, v. 92, n. 3, p. 235-268, 2016. doi: https://doi.org/10.1080/00130095.2015.1116369.

POLANYI, K. A subsistência do homem e ensaios correlatos. Rio de Janeiro: Contraponto, 2012[1977].

POLANYI, K. A grande transformação. Rio de Janeiro: Campus, 1980[1944].

SANFELICI, D. Financeirização e a produção do espaço urbano no Brasil: uma contribuição ao debate. EURE, v. 39, n. 118, p. 27-46, 2013. 
SILVEIRA, M. L. Finanças, consumo e circuitos da economia urbana na cidade de São Paulo. Caderno CRH, v. 22, n. 55, p. 65-76, 2009. doi: https://doi.org/10.1590/ S0103-49792009000100004.

SRNICEK, N. Platform capitalism. Cambridge: Polity, 2016.

STORPER, M. The regional world: territorial development in a global economy. New York: Guilford, 1997.

THOMPSON, E. P. Costumes em comum: estudos sobre a cultura popular tradicional. São Paulo: Companhia das Letras, 1998.

TONUCCl, J. Comum urbano: a cidade além do público e do privado. Tese (Doutorado em Geografia) - Instituto de Geociências, Universidade Federal de Minas Gerais, Belo Horizonte, 2017.

TOPALOV, C. La urbanización capitalista: algunos elementos para su análisis. México: Edicol, 1979 